\title{
Nonplanar Push-Pull Chromophores for Opto-Electronic Applications
}

\author{
Benjamin Breiten ${ }^{\mathrm{a}}$, Ivan Biaggiob ${ }^{\mathrm{b}}$, and François Diederich*a
}

\begin{abstract}
Donor-substituted cyanoethynylethenes (CEEs) are planar push-pull chromophores featuring intense intramolecular charge-transfer (CT) interactions and high third-order optical nonlinearities. Their thermal stability allows for the formation of crystalline thin films by vapor-phase deposition. On the other hand, high-quality amorphous thin films are preferred for opto-electronic applications and such films can be prepared using nonplanar push-pull chromophores with a less pronounced propensity to crystallize. By taking advantage of a versatile, atom-economic 'click-chemistry'-type transformation, involving a formal [2 + 2] cycloaddition of tetracyanoethene (TCNE) to electron-rich alkynes, followed by cycloreversion, stable donor-substituted 1,1,4,4-tetracyanobuta-1,3-dienes (TCBDs) are obtained in high yield and large quantities. These nonplanar push-pull chromophores also feature intense intramolecular CT and, in many cases, high third-order optical nonlinearities. Some of these compounds form high-optical-quality amorphous thin films by vapor-phase deposition, and first applications in next-generation opto-electronic devices have already been demonstrated. Chiral derivatives display high helical twisting power and are efficient dopants to translate molecular into macroscopic chirality, by switching nematic into cholesteric liquid crystalline phases.
\end{abstract}

Keywords: Alkynes · Charge-transfer · Cycloaddition · Donor-acceptor systems · Nonlinear optics

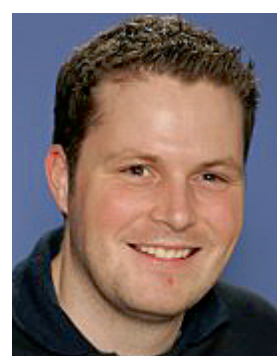

\section{Benjamin Breiten} was born in Neuwied, Germany, in 1982. He graduated from the Heinrich Heine University Duesseldorf, Germany in 2007. Since 2008 he is a PhD student in the group of Prof. François Diederich at ETH Zürich. His research interests focus on the development of functional $\pi$-conjugated architectures based on acetylenic scaffolding.

\footnotetext{
${ }^{\star}$ Correspondence: Prof. Dr. F. Diederich ${ }^{\mathrm{a}}$

Tel.: + 4116322992

Fax: + 4116321109

E-mail: diederich@org.chem.ethz.ch

aLaboratorium für Organische Chemie der

Eidgenössischen Technischen Hochschule

Hönggerberg, $\mathrm{HCl}$

$\mathrm{CH}-8093$ Zürich

'Lehigh University

Department of Physics and Center for Optical Technologies

16 Memorial Dr. East

Bethlehem, PA 18015, USA
}

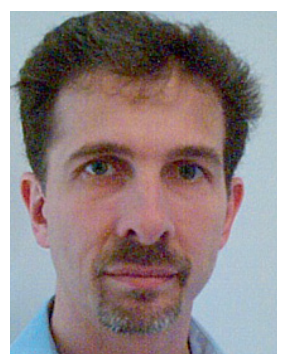

Ivan Biaggio

received his master degree and $\mathrm{PhD}$ degree in physics from the Swiss Federal Institute of Technology (ETH) in Zurich. He was a Postdoc at the University of Southern California and at the Institut d'Optique in Orsay, France, after which he returned to the ETH where he obtained the venia legendi (habilitation) and where he served as a team-leader and 'Privatdozent' until 2002, working on photorefractive effects, nonlinear optics, and optoelectronics. In 2002, he moved to Lehigh University where he set up a research group working on time-resolved laser spectroscopy, nonlinear optics, and charge-carrier photoexcitation and transport.

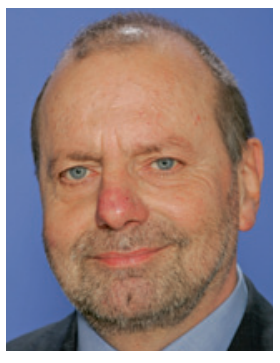

François Diederich was born in 1952 in the Grand-Duchy of Luxembourg and studied chemistry at the University of Heidelberg, where he obtained his diploma (1977), doctoral (1979), and habilitation (1985) degrees. From 1979 to 1981, he was a postdoctoral fellow at UCLA, where he returned in 1985 as an acting associate professor. In 1989, he became full professor and in 1992, he moved to his current position at the ETH Zürich. His research interests are in carbon-rich (fullerenes, acetylenes) molecular architectures, opto-electronic materials, supramolecular chemistry on surfaces, molecular recognition, and structure-based drug design.

\section{Introduction}

Highly conjugated organic molecules, featuring tunable structural and opto-electronic properties, have been recognized as promising candidates for use in electronic and opto-electronic devices. ${ }^{[1-3]}$ Compared to their inorganic counterparts, organic materials are of particular interest due to the ease of structural variation to enhance specific properties for specialized applications and the low costs of their fabrication. ${ }^{[4,5]}$ Their highly polarizable $\pi$-conjugated structures frequently result in efficient second- and third-order nonlinear optical (NLO) responses. ${ }^{[6-9]}$

Molecular organic donor-acceptor (D- $\pi$-A) chromophores, in particular, not only show strong second-order nonlinear optical responses but also enhanced thirdorder nonlinear optical polarizabilities. ${ }^{[10]}$ Most of the known D- $\pi$-A molecules are planar structures in order to ensure efficient $\pi$-conjugation between donor and acceptor. As a result of strong $\pi-\pi$ stacking interactions and antiparallel molecular dipole alignment in the solid state, they tend to form crystalline films. For use in electronic and opto-electronic devices, however, amorphous thin films, which 


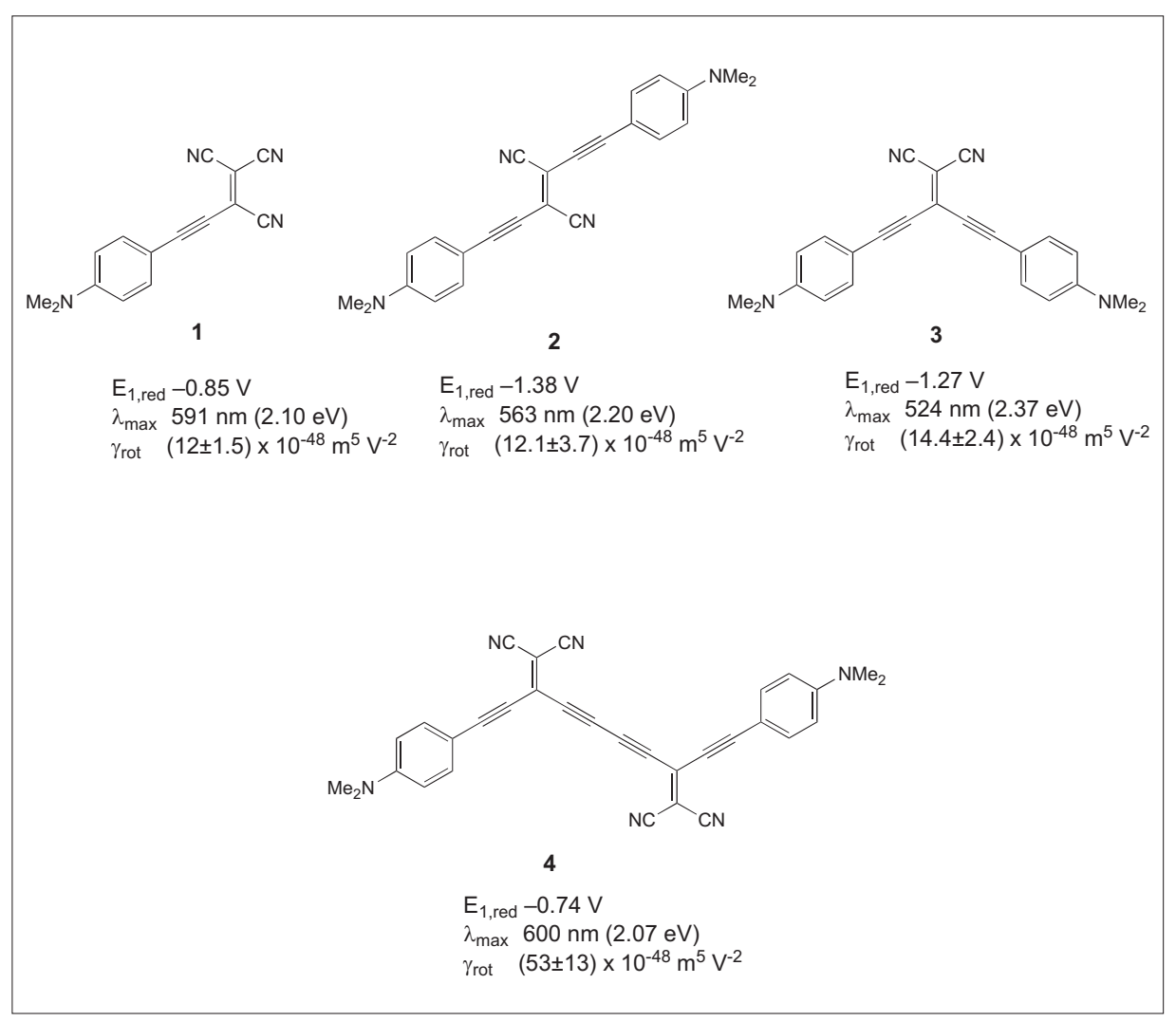

Fig. 1. Examples of donor-substituted cyanoethynylethenes (CEEs) 1-4. Given are the reversible first one-electron reduction potentials $\mathrm{E}_{1, \text { red }}(\mathrm{V})$ in $\mathrm{CH}_{2} \mathrm{Cl}_{2}\left(+0.1 \mathrm{MnBu}_{4} \mathrm{NPF}_{6}\right.$, vs. $\left.\mathrm{Fc} / \mathrm{Fc}\right)$, the maxima of the intramolecular CT bands $\lambda_{\text {max }}\left(\mathrm{nm}\right.$ and eV) in $\mathrm{CH}_{2} \mathrm{Cl}_{2}$ at $298 \mathrm{~K}$, and the third-order polarizability $\gamma_{\text {rot }}$ measured by degenerate four-wave mixing (DFWM) experiments in $\mathrm{CH}_{2} \mathrm{Cl}_{2}$.

can achieve high homogeneity and a high optical quality over large areas, are preferred. Thus, a key issue in our research has become molecular design to control the morphology of thin films. We found that nonplanar D- $\pi$-A push-pull chromophores have certain advantages in terms of solubility, aggregation, and sublimability over their planar counterparts, thereby enabling the formation by vapor-phase deposition of high-optical-quality amorphous thin films for use in opto-electronic devices. ${ }^{[11-13]}$ These recent developments in our laboratories are summarized in this article.

\section{Cyanoethynylethenes}

In the early 2000s, the Diederich group introduced a new class of planar CT chromophores, the donor-substituted cyanoethynylethenes (CEE), such as 1-4,[14-17] and demonstrated their outstanding optoelectronic properties which include intense low-energy CT bands and facile electron uptake capability (Fig. 1). The third-order NLO properties were investigated by degenerate four-wave mixing (DFWM), resulting in extraordinarily large third-order optical nonlinearities, relative to the small molecular mass of the chromophores. ${ }^{[18]}$ scribed in the following years, only a few examples of TCNE additions to organodonor-substituted alkynes had been investigated. ${ }^{[22,23]}$

In systematic and comprehensive studies since 2005, we showed that alkynes, substituted by a variety of organic donors, generally undergo facile, high-yielding $[2+2]$ cycloaddition with TCNE, followed by cycloreversion of the initially formed cyclobutenes, to give nonplanar donorsubstituted TCBDs, such as 5-11. ${ }^{[22,24-28]}$ (Scheme 1). Some of these atom-economic conversions, with the character of 'click'reactions, even proceed quantitatively in the absence of solvent, in a ballmill or using mortar and pestle. Despite their pronounced nonplanarity, the resulting pushpull chromophores feature intense intramolecular charge-transfer interactions.

Donor-substituted TCBDs are thermally stable up to $300{ }^{\circ} \mathrm{C}$, as determined by thermogravimetric analysis (TGA), and can be sublimed without decomposition. DDMEBT (7, 2-[4-(dimethylamino)phenyl]3-([4(dimethylamino)phenyl]-ethynyl) buta-1,3-diene-1,1,4,4-tetracarbonitrile) shows a large third-order nonlinear optical response with $\gamma_{\text {rot }}=12 \pm 2 \times 10^{-48} \mathrm{~m}^{5} \mathrm{~V}^{-2}$. [24] This value is comparable to the highest values obtained for planar, donor-acceptor substituted tetraethynylethenes (TEEs) and other potent NLO chromophores and is quite significant, considering the small number of delocalized $\pi$-electrons in the nonplanar chromophore.

Both high stability and easy accessibility of larger compound quantities make donor-substituted TCDBs attractive chromophores for the fabrication of opto-electronic devices. DDMEBT is especially important in this context because it does not form crystalline films by vapor-phase deposition, but rather produces high-opticalquality amorphous thin films (Fig. 2).[11] This desirable film-forming behavior is a direct consequence of the nonplanarity of the push-pull chromophore and the resulting reduced tendency for crystalline selfassociation in the solid state.

Degenerate four-wave mixing measurements on thin films of DDMEBT revealed an exceptionally high isotropic third-order susceptibility with the $\chi^{(3)}$ value of $2 \pm 1 \times 10^{-19} \mathrm{~m}^{2} \mathrm{~V}^{-2}$ at the offresonant wavelength of $1.5 \mu \mathrm{m}$. This value is $\sim 10^{3}$ times larger than the value for fused silica $\left(1.9 \times 10^{-22} \mathrm{~m}^{2} \mathrm{~V}^{-2}\right)$. $^{[1]} \mathrm{A}$ transmission spectrum taken at normal incidence for an amorphous DDMEBT film is shown in Fig. 3 together with the extinction coefficient of the same molecule in solution. The films have a wide transparency range starting at wavelengths above $700 \mathrm{~nm}$, with a modulation in the transmission at longer wavelengths as a result of multiple reflection. Such a clear transmission modulation 


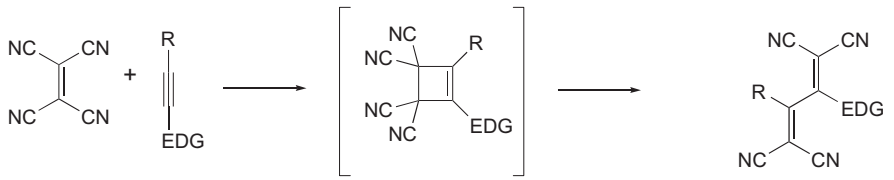

$E D G=$ electron-donating group

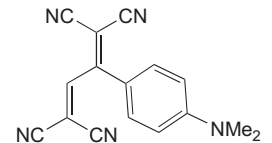

5

$\mathrm{E}_{1, \mathrm{red}}-0.69 \mathrm{~V}$

$\lambda_{\max } 570 \mathrm{~nm}(2.18 \mathrm{eV})$

$\gamma_{\mathrm{rot}} 4 \times 10^{-48} \mathrm{~m}^{5} \mathrm{~V}^{-2}$

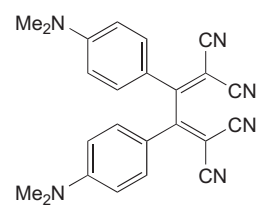

6

$\mathrm{E}_{1, \text { red }}-1.06 \mathrm{~V}$ $\lambda_{\max } 470 \mathrm{~nm}(2.64 \mathrm{eV})$

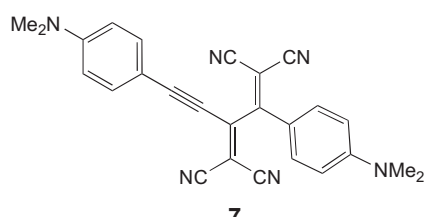

DDMEBT

$\mathrm{E}_{1, \text { red }}-0.89 \mathrm{~V}$

$\lambda_{\max } 526 \mathrm{~nm}(2.36 \mathrm{eV})$

$\gamma_{\text {rot }}(12 \pm 2) \times 10^{-48} \mathrm{~m}^{5} \mathrm{~V}^{-2}$

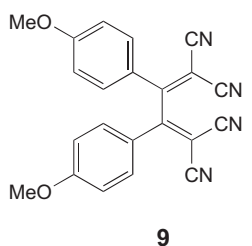

$\mathrm{E}_{1, \text { red }}-0.81 \mathrm{~V}$

$\lambda_{\max } 380 \mathrm{~nm}(3.27 \mathrm{eV})$

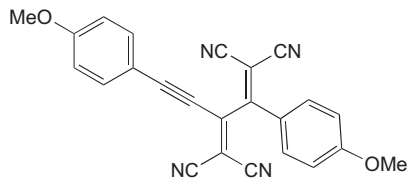

10

$\mathrm{E}_{1, \text { red }}-0.65 \mathrm{~V}$

$\lambda_{\max } 425 \mathrm{~nm}(2.92 \mathrm{eV})$

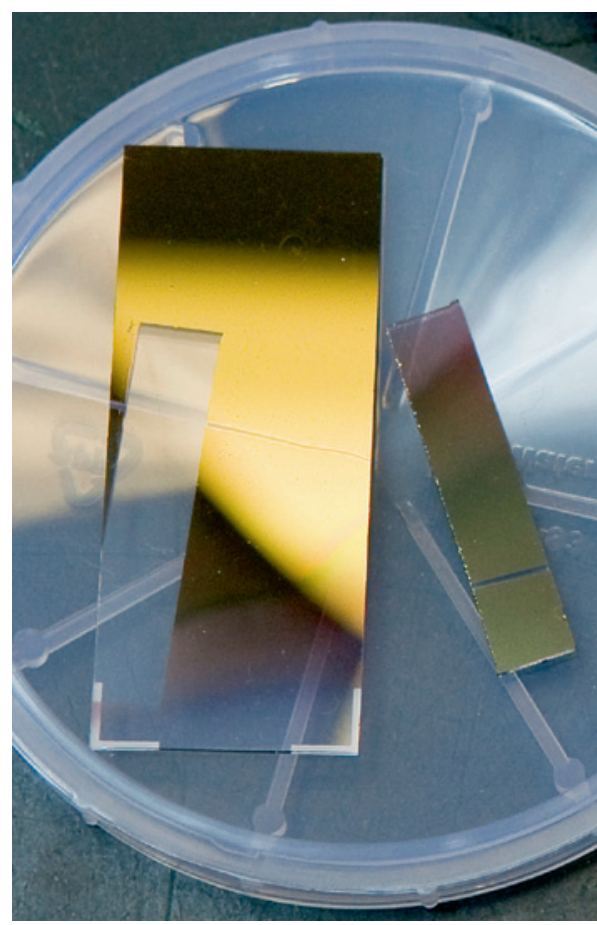

Fig. 2. Photograph of a high-optical-quality amorphous DDMEBT thin film on glass obtained by vapor-phase deposition.

for integration with existing guided-wave photonic technology, and for the development of new hybrid optical devices.

Amorphous films of DDMEBT, obtained by vapor-phase deposition, have been introduced in a multidisciplinary collaboration into highly nonlinear silicon-organic hybrid slot waveguides for all-optical high-speed processing with excellent performance. ${ }^{[11,12]}$ In these hybrid silicon-on-insulator waveguides, the organic material provides the nonlinearity while silicon takes the role of the passive material that provides for waveguiding. In particular, and almost importantly, the vapor deposition process was able to homogenously and completely fill a $160 \mathrm{~nm}$ wide and $220 \mathrm{~nm}$ tall trench between two silicon waveguides (Fig. 5). [11,29] The resulting hybrid waveguide had a record nonlinearity coefficient of $\gamma \approx 1 \times 10^{5} \mathrm{~W}^{-1} \mathrm{~km}^{-1}$ and was the first silicon-organic-hybrid implementation to perform all-optical demultiplexing of a $170.8 \mathrm{~Gb} \mathrm{~s}^{-1}$.[12]

For some time we have also been interested in translating molecular into macroscopic chirality, by developing potent dopants with a high helical twisting power (HTP) to switch nematic into cholesteric liquid crystalline phases. ${ }^{[30,31]}$ For this purpose, we recently prepared the axially chiral, nonplanar push-pull chromophore TCBD $(S, S)-\mathbf{1 1}$ by addition of TCNE to a buta-1,3-diyne activated by two $N$-arylated 3,5-dihydro-4H-dinaphtho[2,1-c:1',2'-e] azepines (' $N$-arylated dinaphthazepines'). Comparative analysis of bond-length al- with wavelength indicates the high quality of the film with respect to small absorption and scattering losses.

Atomic force microscopy (AFM) confirms that the vapor-phase deposited films of $\mathbf{7}$ are homogenous with surface height variations of less than $5 \mathrm{~nm}$ over distances of $0.5 \mu \mathrm{m}$ in films with a thickness of 1 $\mu \mathrm{m}$ (Fig. 4). ${ }^{[11]}$ Many square centimeters of any substrate can easily be covered with such high-quality nonlinear optical film, which makes this an almost ideal material 


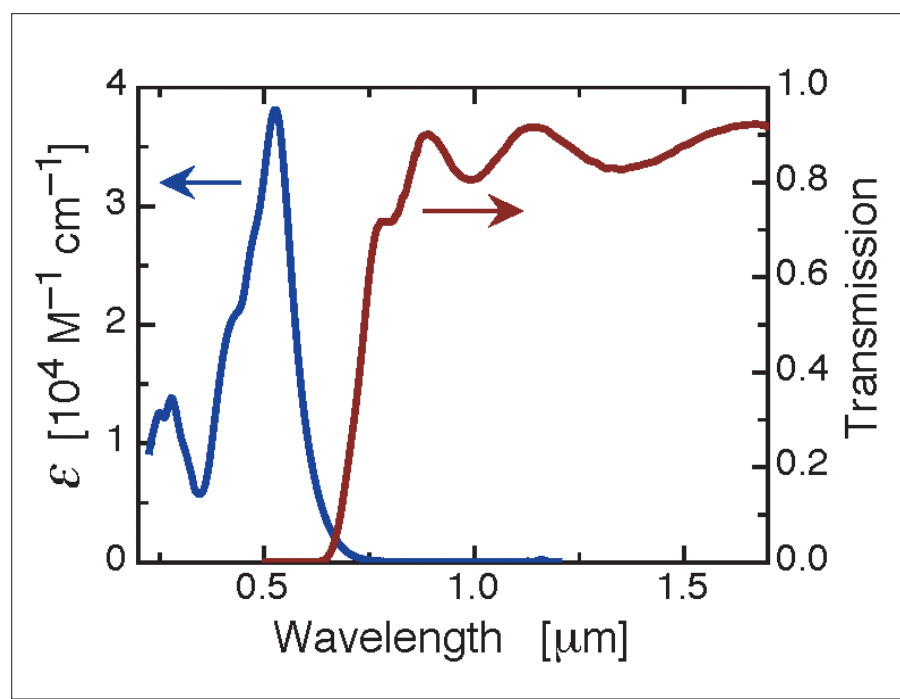

Fig. 3. Molar extinction coefficient of DDMEBT in a $\mathrm{CH}_{2} \mathrm{Cl}_{2}$ solution and transmission spectrum of a $950 \mathrm{~nm}$ thick DDMEBT film deposited on glass. The transmission modulation in the infrared is caused by multiple reflections at the film surfaces.

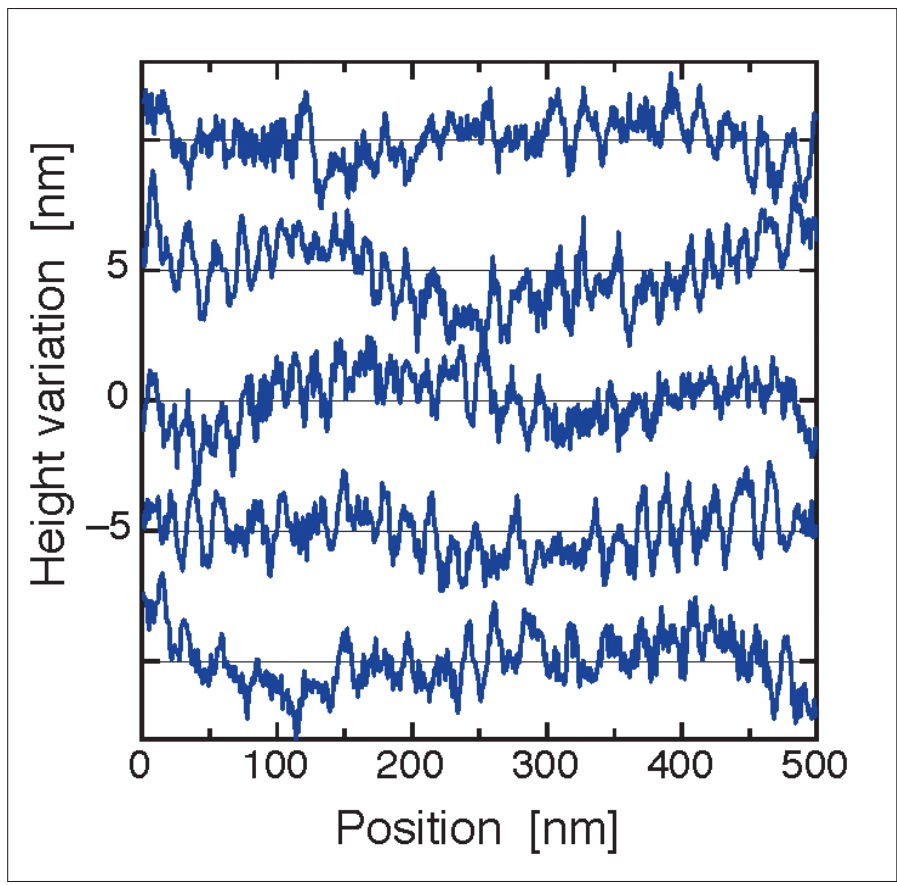

Fig. 4. Atomic force microscope scans showing height variations in an 950 $\mathrm{nm}$ thick DDMEBT film over an area of $500 \mathrm{~nm}$ $\times 500 \mathrm{~nm}$. Shown are five line scans taken every $100 \mathrm{~nm}$, with the data displaced vertically by $5 \mathrm{~nm}$ for clarity.

Rev. 1996, 96, 537

[1] J. M. Tour, Chem. Rev. 1996, 96, 537.
[2] F. Diederich, P. J. Stang, R. R. Tykwinski, 'Acetylene Chemistry', Wiley-VCH, Weinheim, 2005.

[3] S. R. Forrest, M. E. Thompson, Chem. Rev 2007, 107, 923 .

[4] T. W. Kelley, P. F. Baude, C. Gerlach, D. E. Ender, D. Muyres, M. A. Haase, D. E. Vogel, S. D. Theiss, Chem. Mater. 2004, 16, 4413.

[5] J. R. Sheats, J. Mater. Res. 2004, 19, 1974.

[6] R. R. Tykwinski, M. Schreiber, R. P. Carlon, F. Diederich, V. Gramlich, Helv. Chim. Acta 1996, 79, 2249.

Fig. 5.

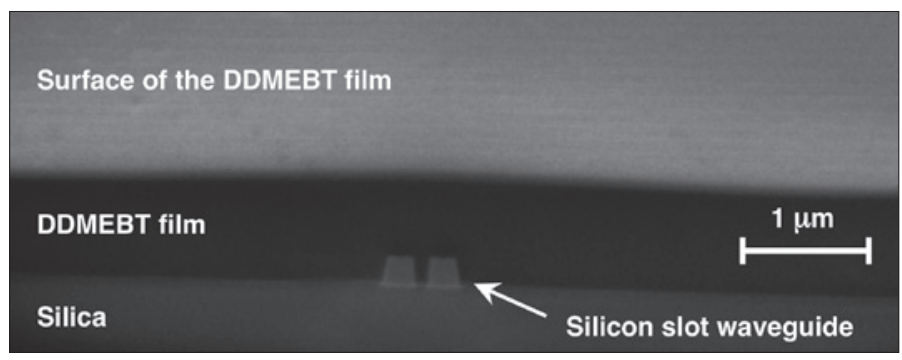

ternation in X-ray diffraction analyses and electrochemical and UV/Vis measurements confirmed that chiral $\mathrm{N}$-arylated dinaphthazepine are similarly potent to achiral $N, N$-dimethylanilino (DMA) moieties in terms of electron donor strength and their capacity to engage in strong intramolecular CT interactions. Additionally as a result of their chirality, they feature high chiroptical responses and are potent cholesteric inducers. Electronic circular dichroism (ECD) spectra of their pushpull chromophores, obtained in the 'click' reaction with TCNE, feature Cotton effects of exceptional intensity with molar circular dichroisms $\Delta \varepsilon$ reaching values above 1000 $\mathrm{M}^{-1} \mathrm{~cm}^{-1}$. With their elongated shape and the rigidity of the chiral $N$-dinaphthazepine donors, push-pull chromophores such as $(S, S)$-11 are also effective inducers of cholesteric supramolecular assemblies in nematic liquid crystals (LCs).[26] Collab-
[7] S. R. Marder, B. Kippelen, A. K. Y. Jen, N Peyghambarian, Nature 1997, 388, 845.

[8] S. R. Marder, Chem. Commun. 2006, 131

[9] R. R. Tykwinski, M. Schreiber, V. Gramlich, P. Seiler, F. Diederich, Adv. Mater. 1996, 8, 226.

[10] J. C. May, I. Biaggio, F. Bures, F. Diederich, Appl. Phys. Lett. 2007, 90, 251106.

[11] C. Koos, P. Vorreau, T. Vallaitis, P. Dumon, W. Bogaerts, R. Baets, B. Esembeson, I. Biaggio, T. Michinobu, F. Diederich, W. Freude, J. Leuthold, Nature Photonics 2009, 3, 216.

[12] B. Esembeson, M. L. Scimeca, T. Michinobu, F. Diederich, I. Biaggio, Adv. Mater. 2008, 20 , 4584.

[13] M. L. Scimeca, I. Biaggio, B. Breiten, F. Diederich, T. Vallaitis, W. Freude, J. Leuthold, Opt. Photonics News 2009, 20, 39.

[14] N. N. P. Moonen, C. Boudon, J. P. Gisselbrecht, P. Seiler, M. Gross, F. Diederich, Angew. Chem. Int. Ed. 2002, 41, 3044.

[15] N. N. P. Moonen, R. Gist, C. Boudon, J. P. Gisselbrecht, P. Seiler, T. Kawai, A. Kishioka, M. Gross, M. Irie, F. Diederich, Org. Biomol. Chem. 2003, 1, 2032.

[16] N. N. P. Moonen, W. C. Pomerantz, R. Gist, C. Boudon, J. P. Gisselbrecht, T. Kawai, A. Kishioka, M. Gross, M. Irie, F. Diederich, Chem. Eur. J. 2005, 11, 3325. 
[17] N. N. P. Moonen, F. Diederich, Org. Biomol. Chem. 2004, 2, 2263.

[18] J. C. May, J. H. Lim, I. Biaggio, N. N. P. Moonen, T. Michinobu, F. Diederich, Opt. Lett. 2005, 30, 3057.

[19] G. Y. Jiang, T. Michinobu, W. F. Yuan, M. Teng, Y. Q. Wen, S. X. Du, H. J. Gao, L. Jiang, Y. L. Song, F. Diederich, D. B. Zhu, Adv. Mater. 2005, 17, 2170.

[20] M. Kivala, F. Diederich, Acc. Chem. Res. 2009, 42, 235.

[21] M. I. Bruce, J. R. Rodgers, M. R. Snow, A. G. Swincer, J. Chem. Soc., Chem. Comm. 1981, 271

[22] For a review, see: S.-I. Kato, F. Diederich, Chem. Commun., in press.

[23] For an early example of TCNE additions to organo-donor-substituted alkynes, yielding NLO-active molecules, see: C. Cai, I. Liakatas, M.-S. Wong, M. Bösch, C. Bosshard, P. Günter, S. Concilio, N. Tirelli, U. W. Suter, Org. Lett. 1999, 1,1847 .

[24] T. Michinobu, J. C. May, J. H. Lim, C. Boudon, J. P. Gisselbrecht, P. Seiler, M. Gross, I. Biaggio, F. Diederich, Chem. Commun. 2005, 737 .
[25] T. Michinobu, C. Boudon, J. P. Gisselbrecht, P. Seiler, B. Frank, N. N. P. Moonen, M. Gross, F. Diederich, Chem. Eur. J. 2006, 12, 1889.

[26] B. B. Frank, B. C. Blanco, S. Jakob, F. Ferroni, S. Pieraccini, A. Ferrarini, C. Boudon, J. P. Gisselbrecht, P. Seiler, G. P. Spada, F. Diederich, Chem. Eur. J. 2009, 15, 9005.

[27] M. Kivala, C. Boudon, J. P. Gisselbrecht, P. Seiler, M. Gross, F. Diederich, Angew. Chem. Int. Ed. 2007, 46, 6357.

[28] P. Reutenauer, M. Kivala, P. D. Jarowski, C. Boudon, J. P. Gisselbrecht, M. Gross, F. Diederich, Chem. Commun. 2007, 4898.

[29] T. Vallaitis, S. Bogatscher, L. Alloatti, P. Dumon, R. Baets, M. L. Scimeca, I. Biaggio, F. Diederich, C. Koos, W. Freude, J. Leuthold, Opt. Express 2009, 17, 17357.

[30] G. Proni, P. G. Spada, P. Lustenberger, R. Welti, F. Diederich, J. Org. Chem. 2000, 65, 5522.

[31] R. Eelkema, B. L. Feringa, Org. Biomol. Chem. 2006, $4,3729$.

[32] M. Kivala, P. D. Jarowski, G. Gescheidt, F. Diederich, Chem. Eur. J. 2009, 15, 4111. 